\begin{tabular}{|l|l|}
\hline & \\
&
\end{tabular}

\title{
Políticas para pessoa com deficiência e as contribuições de Freire e Montessori
}

\author{
Policies for persons with disabilities and the contributions of Freire and Montessori
}

\author{
Jocenir de Oliveira \\ Silva ${ }^{1}$ \\ orcid.org/0000-0001-8768-7607 \\ jocenirsilva@unipampa.edu.br
}

\section{Idilia Fernandes ${ }^{2}$}

orcid.org/0000-0002-9860-638X

idilia-fernandes@faders.rs.gov.br

\section{Luisa Righi Fonseca ${ }^{1}$}

orcid.org/0000-0001-8135-7789

luisarighi@hotmail.com

Recebido em: 6 dez. 2019

Aprovado em: 27 abr. 2020.

Publicado em: 30 out. 2020.

\section{(c) (i)}

Artigo está licenciado sob forma de uma licença Creative Commons Atribuição 4.0 Internacional.
Resumo: A temática central deste artigo versa sobre o atendimento das Pessoas com deficiência, busca-se, deste modo, inferir sobre algumas contribuições históricas a partir da pedagogia proposta por Paulo Freire e Maria Montessori. Apesar de em estudos preliminares Freire não ter tratado diretamente sobre o tema pessoa com deficiência, traz em suas obras um vasto material que dividiu barreiras entre a educação para poucos e a sua democratização. Freire (2013, p.47) defende que a Educação é um processo em que o sujeito deve apreender através da sua vivência, não se evolui recebendo conhecimentos prontos, ou seja: "ensinar não é transferir conhecimentos, mas criar as possibilidades para a sua própria produção ou a sua construção". Deste modo, permite-se estabelecer uma relação entre a pedagogia de Paulo Freire e a política educacional para as pessoas com deficiência, pois ambas desejam que todas as pessoas da sociedade tenham acesso à política de educação. Já a pedagogia proposta por Maria Montessori está inter-relacionada com a inclusão das pessoas com deficiência, uma vez que os seus estudos inicialmente voltaram-se para a educação de crianças com deficiência intelectual.

Palavras-chave: Pessoas com deficiência. Pedagogia montessoriana. Pedagogia freireana.

Abstract: The central theme of this article deals with the care of People with disabilities, thus seeking to infer some historical contributions from the pedagogy proposed by Paulo Freire and Maria Montessori. Although in preliminary studies Freire did not deal directly with the topic of people with disabilities, he brings in his works a vast material that divided barriers between education for the few and their democratization. Freire (2013, p.47) argues that Education is a process in which the subject must learn through their experience, it does not evolve by receiving ready knowledge, that is: "teaching is not transferring knowledge, but creating the possibilities for its own production or its construction". In this way, it is possible to establish a relationship between Paulo Freire's pedagogy and educational policy for people with disabilities, as both want that all people in society have access to education policy. The pedagogy proposed by Maria Montessori is interrelated with the inclusion of people with disabilities, since her studies initially focused on the education of children with intellectual disabilities. Keywords: People with Disabilities. Montessorian Pedagogy. Freirean Pedagogy.

\section{Introdução}

A Convenção Internacional dos Direitos das Pessoas com Deficiência (2007) define em seu primeiro artigo que pessoas com deficiência são aquelas que têm impedimentos de longo prazo, de natureza física, mental, intelectual ou sensorial, os quais, em interação com diversas barreiras, podem obstruir sua participação plena e efetiva na sociedade, em igualdade de condições com as demais pessoas (BRASIL, 2008).

\footnotetext{
Universidade Federal do Pampa (Unipampa), São Borja, RS, Brasil.

Fundação de Articulação e Desenvolvimento de Políticas Públicas para Pessoas com Deficiência e com Altas Habilidades no Rio Grande do Sul (FADERS), Porto Alegre, RS, Brasil.
} 
O tema das pessoas com deficiência, bem como necessidades demandadas pelas mesmas, possui relevância na construção das políticas públicas. Há importância social no sentido de que os resultados evidenciados por pesquisas podem potencializar discussões acerca dos direitos a serem garantidos para a população. Conforme dados da Organização das Nações Unidas (ONU) publicados em 2006, estima-se que 15\% da população mundial tenha alguma deficiência. No Brasil esse índice sobe para $23.9 \%$, significando mais de 46 milhões de brasileiros (IBGE, 2010).

\section{A pessoa com deficiência: diferentes facetas históricas}

A existência de pessoas com deficiência (PCD) na história da humanidade encontra-se suficientemente confirmada, até mesmo na idade antiga. ${ }^{3}$ Soares (2015) menciona a história de Shanidar I, ${ }^{4}$ que teria vivido há mais de 35.500 anos atrás. Ele apresentava deficiência na omoplata, a clavícula e o úmero do lado direito, era cego do olho esquerdo e possuía ainda outras deficiências, e mesmo nessas circunstâncias, ainda que com muitas dificuldades, conseguiu viver em sua tribo.

Historicamente emergem relatos que indicam, considerando condições de sobrevivência, a eliminação de crianças com deficiência intelectual ou com as mais graves deficiências físicas. Nestes casos, a familia era encarregada de extinguir o familiar com deficiência. As pessoas que, porventura, conseguissem sobreviver e fossem descobertas eram consideradas possuidoras de espíritos malignos, ou ainda, resultado de manifestações dos deuses.

[...] Platão considerava que as crianças que nasciam deformes deviam ser rechaçadas e Aristóteles opinava que nenhuma criança deforme merecia viver. Posteriormente, nas sociedades Ateniense e Espartana, aumentou a prática do infanticídio com crianças que mostravam deficiências físicas ou morais, como consequência do culto à destreza e a preparação para a guerra. Neste mesmo sentido podemos dizer que em Roma se praticou tanto o infanticídio como o abandono, a venda e a mutilação, embora o nível econômico familiar fosse uma variável importante na vida do deficiente (CARDOSO, 2008, p.19-20).

Em Esparta as crianças com deficiência eram abandonadas em montanhas, em Roma eram jogadas em rios, pois eram consideradas inúteis. Nota-se através dessas afirmativas que vem de longo tempo a resistência as pessoas com deficiência, e pode-se verificar como suas vidas estavam constantemente ameaçadas. Nesse período, as atitudes das pessoas sem deficiência em relação às pessoas com deficiência iam desde o abandono em florestas, ao extermínio nos desfiladeiros. Outros relatos evidenciam que entre os romanos também eram frequentes atitudes de extrema exclusão em relação às diferentes características humanas.

Nós matamos os cães danados e touros ferozes, degolamos ovelhas doentes, asfixiamos recém-nascidos mal constituidos; mesmo as crianças, se forem débeis ou anormais, nós as afogamos, não se trata de ódio, mas da razão que nos convida a separar das partes sãs aquelas que podem corrompê-las (MISÉS, 1977, p. 14).

Já na Idade Média (século $V$ ao século. XV) as pessoas com deficiência eram associadas à imagem do diabo e a atos de feitiçaria, sendo muitas vezes, perseguidas e executadas. Precisavam ser separadas do convívio social e até mesmo sacrificadas, pois, pertenciam a um grupo que era totalmente excluído da sociedade (CARDOSO, 2008). Dessa forma, como eram "possuídas pelo demônio", deveriam morrer. Frequentemente eram apedrejadas publicamente ou queimadas nas fogueiras da Inquisição. Segundo Kalakun (2010, p. 75) a deficiência foi "historicamente e simbolicamente considerada fator de exclusão social, e as narrativas místicas contam sobre rejeição, a punição e a exclusão dos sujeitos com deficiência em consequência de sua aparência física". Assim, a pessoa com deficiência é afastada do convívio social, pois, não é percebida

\footnotetext{
Periodo datado até o ano de 453 d.C., quando ocorre a queda do Império Romano do Ocidente.

Apelidado de Nandy, Shanidar1 viveu em algum momento entre 45.000 e 35.000 anos atrás. Ele teve uma vida dura. Uma pancada na cabeça em sua juventude provavelmente cegou o seu olho esquerdo. O braço e a perna direita eram atrofiados, sugerindo que a lesão na cabeça provavelmente também causou dano cerebral que paralisou o lado direito do corpo de Nandy. Ele também fraturou o pé em algum ponto. No entanto, todos os seus ossos mostraram sinais de cura, e Nandy viveu para ser um idoso por padrões de neanderthal. morrendo em algum momento entre as idades de 35 e 45 anos. A descoberta revelou que os neanderthais devem ter cuidado de seus doentes, feridos e pessoas com deficiência (SOARES, 2015)
} 
como pertencente a um determinado grupo social, portanto, esse indivíduo carrega um estigma que the é imposto pela sociedade.

O estigma é definido como uma diferença não desejada, um atributo pejorativo que implica na intolerância do grupo ao qual pertence. Percebe-se que historicamente não foram apenas aqueles cidadãos com deficiência que foram segregados, mortos ou arrastados para os manicômios, mas também todos aqueles que eram considerados indesejáveis (GOFFMAN, 1891). A sociedade tende a rejeitar, excluindo todos aqueles que não se enquadram em padrões como se não fizessem parte dela. Goffman (1891) afirma que poderão ser chamados de "normais" todos aqueles que não sofrem nenhum tipo de estigma, e que o estigma é formulado por todas as esferas da sociedade. inclusive pelo próprio grupo estigmatizado.

Por definição, fazemos vários tipos de discriminações, através das quais efetivamente, e muitas vezes sem pensar, reduzimos suas chances de vida. Construímos uma teoria do estigma, uma ideologia para explicar a sua inferioridade e dar conta do perigo que ela representa, racionalizando algumas vezes uma animosidade baseada em outras diferenças, tais como as de classe social. Utilizamos termos específicos de estigma como aleijado, bastardo, retardado em nosso discurso diário como fonte de metáfora e representação, de maneira característica, sem pensar no seu significado original (GOFFMAN, 1891, p. 8).

O estigma é uma criação social que isola as pessoas, e acaba por classificar os sujeitos como indesejáveis desvalorizando e excluindo. Impõe culturalmente que o estigma se torne superior às outras características da identidade, contribuindo para desvalorização do sujeito. O estigmatizado é discriminado e acaba por rejeitar seus próprios semelhantes, já que é capaz de reconhecer no outro aquilo que nele é considerado "anormal".

A partir do século XVIII, algumas mudanças de atitudes começaram a ser introduzidas pela filosofia de Rousseau e Diderot, uma vez que, pretendiam que o ensino fosse para todas as pessoas e que tivesse como base a inclusão. Já nos séculos XIXe XX,

as ideias de Montessori, Decroly, Froebel, Dewey, Makarenko, Mendel, Freinet, e tantos outros reforçaram a necessidade da escola estar aberta à vida, ao mesmo tempo em que devia ser obrigatória para todos e não só para os filhos dos favorecidos economicamente e/ ou privilegiados (CARDOSO, 2008, p. 21).

Não se pretende aqui depositar na educação ou em qualquer outra política isoladamente a perspectiva de salvadora dos sujeitos estigmatizados, mas defende-se que o conjunto da teia das relações sociais deva superar o estigma afim de possibilitar 0 atendimento de todos/as na sociedade.

Ainda no século XVIII, Abade L'epée (17121789) criou na França a primeira escola para "surdos-mudos" e Hauy (1745-1822) fundou em Paris a primeira escola para crianças cegas, estabelecendo que os cegos também pudessem acessar a educação. No século XX foram criados centros de isolamento para o atendimento, onde se pretendia que as Pessoas com Deficiência tivessem um convívio no interior desses lugares, aquém da sociedade, mantendo-as invisiveis para a maior parte da população. Isto contribuiu para que a sociedade em geral acreditasse que o motivo para a segregação estava na pessoa com deficiência, que essa não poderia pertencer à mesma sociedade porque não seria capaz de se integrar, quando na verdade sempre foi a própria sociedade que the impediu o acesso.

No fim do século XVIII e começo do século XIX, iniciou-se, nos países escandinavos e na América do Norte, o periodo de institucionalização especializada das pessoas com deficiência e, a partir daí, surge a Educação Especial. Nota-se que nesse periodo a sociedade passa a ter alguma consciência da necessidade em atender as diferentes características das pessoas com deficiência. No entanto, este atendimento passou a ocorrer com caráter assistencial e recreativo, focando na ajuda, e não no papel educativo, logo, pouco avançou na pretensão de educar para alcançar independência e autonomia. Assim,

A separação dos demais, o isolamento, a segregação são consequências que normalmente incidem sobre aqueles que se "desviam do caminho" da padronização. As diversas instituições reproduziram e reproduzem fortemente esse processo social da igualização. Em muitas ocasiões as diferenças não são aceitas; por vezes são reprimidas com atitudes reguladoras e punitivas para que se atinja uma generalização dos comportamentos. A questão da 
normalidade está diretamente ligada à questão da segregação, pois o que não é "normal" é considerado um desvio, algo que deve ficar escondido (FERNANDES, 2012, p. 25).

O periodo da segregação marcado pela instituição das escolas especiais tem como objetivo separar e isolar as crianças com alguma deficiência do convivio comum da sociedade. Nessas instituições, tanto as pessoas com deficiência como outros que fogem dos padrões de "normalidade", são enclausuradas por representarem, de alguma maneira, perigo para a sociedade.

No século XIX, fortaleceu-se um espirito religioso que pregava valores de compaixão e piedade, e ações de assistência às pessoas com deficiência rapidamente difundiram-se, "por meio de doações, de atendimento ou de enclausuramento em centros especializados" (BRASIL, 2007, p. 15). Com isso, a pessoa com deficiência passa a ser vista com sentimento de pena e como totalmente dependente de outras pessoas para sobreviver. Ainda que de modo "atravessado", percebe-se que a partir dessa época começam a acontecer pequenas mudanças em alguns padrões referentes à inclusão. Com o transcorrer do tempo passa-se a pensar no fato de que as Pessoas com Deficiência deveriam fazer parte (pertencer) a alguns campos da sociedade, e não apenas serem vistas como "anormalidades" que deveriam ser totalmente excluidas do convivio social. Conforme Lobo (1997, p. 472), a noção de criança "anormal" no início do século XX era vista como:

Marcada por causas orgânicas, por estigmas físicos, considerada incurável, questionada enquanto doença, a idiotia custou mais a adquirir essa visibilidade nosográfica da psiquiatria. Nem por isso deixou de ser, desde o início, assimilado à alienação ou doença mental, quer nos discursos, quer nas práticas de enclausuramento. É este ponto que nos interessa: a institucionalização de idiotia pelo psiquiatra e que, por extensão, fez nascer no início do século XX a criança anormal.

Na época das Instituições durante o século $X X, 5$ o Modelo Médico predominou, quando a questão da diferença do padrão considerado normal passou da órbita da influência da Igreja para se tornar objeto da Medicina.Neste modelo "a criança com deficiência é considerada como um doente: a atenção que recebe é fundamentalmente do tipo médico [...] e a organização das instituições é a mesma que a dos centros hospitalares" (RUBIO, 1998, p. 19). A única interpretação que se tinha era exclusivamente a do médico, o que excluía qualquer outra forma de intervenção e tratamento, outras formas de compreensão acabavam sendo negadas. Seguin (1866) chegou a fazer uma classificação sobre pessoas com "atraso mental", resumida nos seguintes pontos:

a) Idiotice: termo tomado do grego idiotes, ignorante, grosseiro, atualmente equivaleria a atraso grave ou profundo; b) Imbecilidade: termo do latim imbecilis, débil, debilitado, enfermo, de fraca inteligência, se aplica a pessoas com leve atraso e sérios defeitos de relação social; c) Debilidade Mental: considerado como simples atraso mental; d) Atraso Mental: desenvolvimento intelectual lento (CARDOSO, 2008, p. 24).

O que fica evidente é que a classificação feita em 1846 levou em conta principalmente fatores de ordem moral e de adaptação dos sujeitos na sociedade. Por isso, pode-se afirmar que até o século XIX todos os estudos e classificações feitas sobre as pessoas com deficiência tinham uma orientação médica.

Contemporaneamente, há resquícios muito fortes do modelo médico da deficiência, isso pode ser notado no discurso que declara a pessoa com deficiência como desamparada, pessoa doente, que precisa dos cuidados de outras pessoas permanentemente. O modelo médico da deficiência diz que "tradicionalmente, a deficiência tem sido vista como um 'problema' do indivíduo e, por isso, o próprio individuo teria de se adaptar à sociedade ou ele teria de ser mudado por profissionais através de reabilitação ou cura" (FLETCHER, 1996, p. 7). Para Sassaki (1997, p. 29), seguindo o mesmo modelo médico da deficiência, "a Pessoa com Deficiência é que precisa ser curada, tratada, re-

\footnotetext{
5 Para Goffman (2001), quando essa instituição social se organiza de modo a atender individuos (internados) em situações semelhantes, separando-os da sociedade mais ampla por um periodo de tempo e impondo-lhes uma vida fechada sob uma administração rigorosamente formal (equipe dirigente) que se baseia no discurso de atendimento aos objetivos institucionais, ela apresenta a tendência de "fechamento" o que vai simbolizar o seu caráter "total".
} 
abilitada, habilitada, etc. a fim de ser adequada à sociedade como ela é sem maiores modificações".

[...] se esbarra na grande deficiência do conhecimento e das estratégias dos métodos pedagógicos para lidar com as diferenças e sua perversa consequência direta, ou seja, a segregação. Na falta da compreensão, não se buscou a alternativa para a diversidade; então foi mais fácil separar, excluir, expulsar, desqualificar (FERNANDES, 2012, p. 27).

O modelo médico, segregatório, de atendimento às pessoas com deficiência tem sido muitas vezes responsável pela resistência que a sociedade apresenta em acolher a ideia de mudança de atitude para uma real inclusão das PCD. O modelo médico da deficiência tem como objetivo tornar a PCD uma pessoa 'melhor', fazendo com que sejam adequados aos padrões vigentes na sociedade. No entanto, é preciso ir além, é preciso que sejam levadas em consideração todas as suas necessidades e que sejam atendidas de forma integral. Todos os cidadãos têm direito garantido constitucionalmente no âmbito da educação, saúde, assistência social, entre outros. No "modelo médico da deficiência", as pessoas com deficiência são consideradas doentes, desamparadas, dependentes, inúteis, inválidas, isentas dos deveres comuns. Neste modelo, as pessoas são objetos da atenção institucional e não são sujeitos (FERNANDES, 2012, p. 28). Não obstante seja garantido acesso aos serviços, é necessário rever o modelo de sociabilidade, avançando para uma sociedade que tenha de fato direitos para todos os sujeitos, sem passar pelo crivo concorrencial caracteristico do modo de produção capitalista.

Após longo período no qual prevaleceram as ideias do modelo médico da deficiência, começou a surgir por volta do final da década de 1960 o movimento que procurava inserir as pessoas com deficiência em vários campos da sociedade, como o trabalho, a educação e o lazer. Todo esse movimento que pretendia uma nova maneira de agir em relação às pessoas com deficiência recebeu o nome de integração social, assim: "a ideia de integração surgiu para derrubar a prática da exclusão social a que foram submetidas as pessoas com deficiência por vários séculos" (SASSAKI, 1997 , p. 30). As Pessoas com Deficiência eram e são excluidas das atividades e do convivio em sociedade.

Se algumas culturas simplesmente eliminam as pessoas com deficiência, outras adotaram a prática de interná-las em grandes instituições de caridade, junto com doentes e idosos. Essas instituições eram em geral muito grandes e serviam basicamente para dar abrigo, alimento, medicamento e alguma atividade para ocupar o tempo ocioso (SASSAKI, 1997, p. 1).

Com a execução dessas práticas a segregação institucional continuou sendo a principal ação, o que se pretendia era que dentro dessas instituições todos os serviços possiveis fossem ali disponibilizados às pessoas com deficiência. No começo da década de 1960, "testemunhou-se o boom de instituições especializadas, tais como: escolas especiais, centros de habilitação, centros de reabilitação, oficinas protegidas de trabalho, clubes sociais especiais, associações desportivas especiais" (SASSAKI, 1997, p. 30).

A perspectiva da integração social da pessoa com deficiência, embora dicotômica, trouxe alguns principios que ajudaram a impulsionar uma nova concepção sobre a necessidade de inclusão: o principio da normalização e o princípio do mainstreaming. Na década de 1970 o princípio da normalização foi um movimento que teve como objetivo criar, para as pessoas atendidas em instituições, um ambiente que fosse o mais parecido possivel com o da população em geral. O princípio da normatização

[...] tinha como pressuposto básico a ideia de
que qualquer pessoa portadora de deficiência,
especialmente aquela portadora de deficiência
mental, tem o direito de experiência um estilo
ou padrão de vida que seria comum ou normal
à sua própria cultura (MENDES, 1994, p. 5-6).

A década de 1980 trouxe avanços na tentativa de integração social. Na área da educação especial foram introduzidos os princípios de mainstreaming, "termo que, na maioria das vezes, tem sido utilizado sem tradução e que significa levar os alunos o mais possivel para os serviços educacionais disponiveis na corrente principal da comunidade" (SASSAKI, 1997, p. 32). Para compre- 
ender o movimento do mainstreaming deve-se ter em mente que esse pode ocorrer em muitos ambientes: "pode ocorrer em classes regulares, durante o almoço, em matérias especificas (como música, artes, educação física) e em atividades extracurriculares" (WERNECK, 1995, p. 176).

Esse movimento representou um importante passo na perspectiva da integração social, principalmente das crianças com deficiência, que passaram a frequentar a escola, e isso significou uma forma de integrar, de fazer parte de algo, acontecimento que anteriormente não era possivel. A prática da integração social ganhou maior relevância social com o advento do movimento pela luta dos direitos da pessoa com deficiência a partir de 1990, que, de certa forma, estava associado à ideia de desinstitucionalização que naquele momento histórico prevalecia na sociedade.

Deve-se observar que tanto o principio da normalização, quanto o princípio do mainstreaming trouxeram grandes experiências e conhecimentos aos ideais da integração, e que acabaram abrindo caminhos para o paradigma da Inclusão, movimento que na década de 1990 passou a ter relevância mundial. A integração social da pessoa com deficiência na época vinha, mesmo que de forma controversa, cumprindo com seu objetivo que era de contribuir para a inclusão da pessoa com deficiência, desde que, é claro, essa se adequasse e/ou "enquadrasse" aos padrões da sociedade vigentes. Essa postura não era mais suficiente para atender as bandeiras de luta dos membros da sociedade que estavam engajados na luta pelos direitos da pessoa com deficiência. O movimento da integração social teve o seu principal objetivo alcançado, que era inserir a pessoa com deficiência na sociedade, "mas desde que ela esteja de alguma forma capacitada a superar as barreiras físicas, programáticas e atitudinais nela existentes" (SASSAKI, 1997, p. 33). Essa perspectiva demonstra um esforço tão somente da pessoa com deficiência e de seus familiares para que possa, de forma paulatina, inserir-se no convivio social, tendo as PCD se tornado apenas 'aceitáveis' dentro da sociedade. De acordo com Sassaki (1997, p. 33) a integração social ocorria e ainda ocorre de três formas:
1. Pela inserção pura e simples daquelas pessoas com deficiência que conseguiram ou conseguem, por méritos pessoais e profissionais próprios, utilizar os espaços físicos e sociais, bem como seus programas e serviços, sem nenhuma modificação por parte da sociedade, ou seja, da escola comum, da empresa comum, do clube comum, etc.

2. Pela inserção daquelas pessoas com deficiência que necessitavam ou necessitam alguma adaptação específica no espaço físico comum ou no procedimento da atividade comum a fim de poderem, só então, estudar, trabalhar, ter lazer, enfim, conviver com as pessoas sem deficiência.

3. Pela inserção das pessoas com deficiência em ambientes separados dentro dos sistemas gerais. Por exemplo, escola especial junto à comunidade; classe especial numa escola comum; setor separado dentro de uma empresa comum; horário exclusivo para pessoas com deficiência num clube comum, etc. Esta forma de integração, mesmo com todos os méritos, não deixa de ser segregativa.

Nenhum desses três tipos de integração social é garantidor dos direitos das pessoas com deficiência em sua plenitude, na verdade nenhum tipo de integração social propõe a mudança "de atitudes, de espaços físicos, de objetos e de práticas sociais" (SASSAKI, 1997, p. 34). No modelo de integração social, a sociedade não tem nenhuma participação na transformação que venha a ocorrer, ela aceita receber as pessoas com deficiência, desde que elas estejam preparadas para todos os desafios que irão enfrentar.

Por volta do início da década de 1990, alguns segmentos da sociedade preocupados com a promoção dos direitos das pessoas com deficiência começaram a perceber e a disseminar que a prática da integração social não "só era insuficiente para acabar com a discriminação que havia contra esse segmento populacional, mas também era muito pouco para propiciar a verdadeira participação plena com igualdade de direitos" (SASSAKI, 1997, p. 33). O termo "integração", que nada mais é que uma inserção parcial da 
pessoa com deficiência na comunidade, passou a ser substituido pelo termo "inclusão", que é um esforço coletivo de transformação realizado, agora também pela sociedade e não mais apenas pelas pessoas com deficiência e suas familias. Nessa perspectiva, portanto, cabe à sociedade se transformar e adaptar-se às necessidades da diversidade humana. O conceito de inclusão está associado ao entendimento de que a sociedade precisa ser capaz de atender as necessidades de todos os seus membros, ela deve dispor de meios para que todos os sujeitos possam se desenvolver integralmente. Para Sassaki (2010, p. 39) conceitua-se inclusão como:

[...] o processo pelo qual a sociedade se adapta para poder incluir, em seus sistemas sociais gerais, pessoas com deficiência (além de outras) e, simultaneamente, estas se preparam para assumir seus papéis na sociedade. A inclusão constitui, então, um processo bilateral no qual as pessoas, ainda excluidas, e a sociedade buscam, em parceria, equacionar problemas, decidir sobre soluções e efetivar a equiparação de oportunidades para todos.

O movimento da inclusão prevê a construção de um novo tipo de sociedade, através de transformações que ocorram em todos os campos comuns da coletividade, principalmente uma mudança na forma de pensar e agir das pessoas (com e sem deficiência), para que possam aprender a conviver umas com as diferenças que as outras apresentam. A prática da Inclusão está atrelada a princípios como: aceitação das diferenças individuais, a valorização de cada pessoa, a convivência dentro da diversidade humana, a aprendizagem através da cooperação. Quando essas ideias são materializadas e começam a transformar a sociedade, pode-se "falar em educação inclusiva, no lazer inclusivo, no transporte inclusivo, etc., ou então, falar em uma educação para todos, lazer para todos ou transporte para todos" (SASSAKI, 1997, p. 40). Quanto maior o número de políticas públicas aderindo às ideias do movimento da Inclusão, mais fácil será construir uma sociedade que seja realmente para todos/as, onde nenhuma forma de discriminação e preconceito seja admitida.

Com isso, a Inclusão das Pessoas com Defici- ência não exige apenas uma transformação nos padrões vigentes em apenas uma área específica da sociedade, mas exige que toda a comunidade esteja unida na implementação desse movimento. A política de inclusão deve ir além de propostas e ações fragmentadas, devendo perpassar todos os campos: culturais, politicos, sociais, econômicos e históricos. Esses fatores implicam na construção de uma sociedade inclusiva que respeite às diferenças, onde seja predominante não a condição de pessoas com deficiência, mas sim, sua condição de pessoa humana, e por isso, sujeito de direitos. A sociedade inclusiva pode ser assim caracterizada:

\begin{abstract}
Uma sociedade inclusiva garante seus espaços a todas as pessoas, sem prejudicar aquelas que conseguem ocupá-los só por méritos próprios. Neste ponto, é oportuno acrescentar que o conceito de sociedade inclusiva, introduzido nos meios especializados em deficiência, tornou-se hoje válido também em outros meios, ou seja, naqueles em que estão presentes as pessoas com outras condições atípicas. Além disso, uma sociedade inclusiva vai bem além de garantir apenas espaços adequados para todos. Ela fortalece as atitudes de aceitação das diferenças individuais e de valorização da diversidade humana e enfatiza a importância do permanecer, da convivência, da cooperação e da contribuição que todas as pessoas podem dar para contribuírem em vidas comunitárias mais justas, mais saudáveis e mais satisfatórias (SASSAKI, 1997, p. 172).
\end{abstract}

Pode-se observar que as ideias da Inclusão formam uma sociedade movida pelos direitos humanos, que tem a igualdade e a diferença como valores indissociáveis, e que avança cada vez mais na questão da equidade. Especialistas na área da inclusão acreditam que "as comunidades com diversidades sejam mais ricas, lugares mais produtivos para viver e aprender, e que comunidades inclusivas tenham a capacidade de criar o futuro" (MANTOAN, 1997, p. 141). Assim, a Inclusão é um movimento que envolve todos os campos da sociedade, e que desencadeia a defesa intransigente dos direitos de todas as pessoas, sem nenhuma forma de preconceito ou discriminação, daí a perspectiva de uma maior e melhor qualidade de vida através da Inclusão.

Mesmo com todo o movimento existente no mundo inteiro, inclusive no Brasil, enfatizando a Inclusão como a resposta mais adequada e 
eficiente contra qualquer tipo de discriminação e preconceito, ainda é comum que muitos tenham seus direitos ignorados e/ou violados. É necessário que a sociedade como um todo tenha como eixo norteador o reconhecimento da pessoa com deficiência enquanto sujeito de direito. Isso poderá criar condições para o pleno desenvolvimento de habilidades, capacidades e potencialidades. É possivel afirmar que mesmo que ainda não tenha ocorrido de modo integral o ideal da inclusão, muito já se avançou e se tem avançado na busca de uma sociedade para todos/as. Se for tomado por referência o histórico de exclusão que as pessoas com deficiência atravessaram, pode-se afirmar que o conceito e a prática da inclusão são recentes e, na sociedade com capitalismo maduro, não vem alcançando os resultados de "incluir" toda a diversidade humana.

Gramsci, autor expoente de tradição Marxista, tem posição marcante quanto à necessidade de transformação da sociedade capitalista pela via cultural e política, pela via do protagonismo consciente, ativo e organizado dos homens, desencadeando o processo de rupturas que levará a edificação de uma contra hegemonia (LUIZ, 2012, p. 92, grifo da autora).

Nesse sentido, é importante referir que as políticas públicas têm papel fundamental no que se refere à garantia dos direitos das pessoas com deficiência, pois o acesso das PCD à política social de educação significa uma clara ruptura histórica rumo à conquista de direitos. Pereira (2009, p. 172) afirma que a política social "envolve o exercício do poder praticado, concomitantemente, por individuos, grupos, profissionais, empresários, trabalhadores, entre vários segmentos sociais que tentam influir na sua constituição e direção". Já a política pública:

Expressa a conversão de demandas e decisões privadas e estatais em decisões e ações públicas que afetam e comprometem a todos, trata-se da integração política interpartes com a política superpartes. Por ser pública (e não propriamente estatal ou coletiva e muito menos privada), ela, assim como todas as suas espécies (aí incluida a política social), tem dimensão e escopo que ultrapassam os limites do Estado, dos coletivos ou corporações sociais e, obviamente, do individuo isolado. Por isto, o termo "público" que qualifica como política tem um intrínseco sentido de universalidade e de totalidade (PEREIRA, 2009, p. 174).
Uma política pública de educação - recorte do presente capítulo - tem um sentido mais amplo, enquanto a politica social de educação remete para a objetivação das ações dos diferentes segmentos com ações de Educação. Ambos os conceitos são imprescindiveis na construção do atendimento às pessoas com deficiência, pois remetem para a complexidade de ações na amplitude social, bem como no miúdo das instituições que trabalham com a Educação. Assim, tem-se a possibilidade de formar novas gerações através da inclusão, com nivel cultural e de consciência que permitam a ruptura, resultando na convivência de todos os seres humanos, independentemente das suas diferentes características. Neste sentido, entende-se que as obras de Paulo Freire e Maria Montessori trouxeram importantes contribuições para a ampliação e garantia do direito ao acesso à política de educação. Ambos trabalharam em suas teses a dimensão da universalidade da Educação, logo, contribuiram diretamente para que as pessoas com deficiência pudessem passar a exigir o direito de estarem nas escolas. Esse processo vem lentamente sendo absorvido pela sociedade mesmo contando com o aparato legal para a sua efetivação.

\section{Pedagogia freireana e a universalização da educação}

Apesar do desenvolvimento de sua teoria datar-se anteriormente ao movimento mundial de inclusão, a perspectiva filosófica de Paulo Freire repercute contemporaneamente e evidencia um conceito real de inclusão. A pedagogia freireana com sua práxis libertadora carrega a gênese do conceito da educação inclusiva, que nega o sistema educacional tradicional e a homogeneização dos educandos subordinados aos interesses do capitalismo neoliberal. Volta-se não apenas às Pessoas com Deficiência e os demais excluidos, mas é defendida para todos/as, sem discriminação de qualquer natureza. Institui-se autenticamente como uma pedagogia inclusiva, que, na sua lógica da práxis libertadora, transforma a alteridade entre os sujeitos na medida em que reconhece as diferenças que os constituem e os caracterizam enquanto humanos. 
Se o conhecimento da escola se distancia das necessidades de vida dos alunos, impedindo que eles o assimilem, o resultado escolar será marcado necessariamente pela exclusão daqueles que deveriam dominar este conhecimento, reproduzindo de forma conservadora a vida desigual desta sociedade, onde poder traz saber (KRUPPA, 1994, p. 31).

Freire (1921-1997), ao considerar sua vasta contribuição para área da educação e da pedagogia, expunha como tarefa primordial da educação, do ensino e da escola a restituição da dignidade do aluno, da libertação e, advindo disto, a humanização da sociedade (ARANHA, 2006). Em concepções freireanas, a humanização da sociedade é intrínseca à natureza humana, e, sendo assim inerente, apenas realiza-se a partir da libertação de aspectos que levam à desumanização. Desse modo, a pedagogia de Paulo Freire posiciona-se comprometida com uma sociedade humanizada, liberta e fundamentalmente ética, convergindo-se, assim, para uma vida em totalidade (ZITKOSKI, 2007). Ao referir-se sobre Freire, Jorge (1979, p. 24) discorre que:

Libertar, pois, o homem oprimido desta realidade desumanizante, desta "coisificação", desta situação de "objetos", de "ser menos", para ser "mais", isto é, adquirir a própria dignidade humana perdida, realizar sua vocação histórica, tornou-se o objetivo principal de Paulo Freire e o ideal de sua luta.

Centrando-se na análise de algumas obras de Freire, percebe-se sua preocupação coerente em reiterar sobre a concepção de uma educação conservadora e suas práticas desumanizantes, que ao contrário de afirmar o/a aluno/a enquanto sujeito autônomo e criativo, oprime este aluno, pondo-o/a em uma situação de inferioridade. Na perspectiva de opressão, a escola como um todo não exerce sua função de satisfação das necessidades educativas de todos/as e para todos/as, de uma escola inclusiva, mas persiste na lógica de segregação, exclusão e opressão. Ao pensar uma pedagogia humanista e libertadora, Freire (2014, p. 57) aponta dois momentos distintos:

O primeiro, em que os oprimidos vão desvelando o mundo da opressão e vão comprometendo-se, na práxis, com a sua transformação; o segundo, em que, transformada a realidade opressora, esta pedagogia deixa de ser do oprimido e passa a ser a pedagogia dos homens em processo de permanente libertação.

Deste modo, pode-se situar as práticas inclusivas da Pessoa com Deficiência como um ato de libertação dos sujeitos historicamente mantidos segregados. Freire (2014) parte de que se vive em uma sociedade dividida em classes na qual os privilégios de uns impedem a maioria de usufruirem os bens socialmente produzidos.

Nesse sentido, Stainback e Stainback (2009, p. 24) afirmam que "as turmas segregadas não conduzem à independência e à competência, mas estimulam uma sensação irrealista de isolamento [...] além de gerar um sentimento de inferioridade com relação à situação". Ao incluir as pessoas com deficiência nas escolas e demais ambientes da sociedade, está-se, nessa lógica, garantindo uma microrruptura nas relações de poder até então estabelecidas. A opressão afirma-se pelo não acesso aos bens culturais, sociais e políticos, e os oprimidos somente poderão romper com a opressão no exercício das liberdades, no acesso à justiça, na luta pela recuperação de sua humanidade roubada.

Quem, melhor que os oprimidos, se encontrará preparado para entender o significado terrivel de uma sociedade opressora? Quem sentirá, melhor que eles, os efeitos da opressão? Quem, mais que eles, para ir compreendendo a necessidade da libertação? Libertação a que não chegarão pelo acaso, mas pela práxis de sua busca; pelo conhecimento e reconhecimento da necessidade de lutar por ela (FREIRE, 2014, p. 42-43).

Na dimensão em que se segregam as Pessoas com Deficiência, excluindo-as do acesso à escola regular, concomitantemente está se evidenciando a relação opressor-oprimido. Assim, as contribuições de Freire, que naquele momento visavam à democratização do acesso à educação, aplicam-se também para problematizar o acesso à política de educação para as pessoas com deficiência. Dorea (2008) afirma que a pedagogia desafiadora proposta por Freire é necessária para o desenvolvimento da ética fundamentada no diálogo entre as diferenças, e enquanto estudioso da obra de Freire e da educação inclusiva, aponta que: 
Trata-se de pensar os homens como seres em constante devir e não como indivíduos prontose acabados, alguns até circunscritos, por exemplo, sob os rótulos de inferiores e mesmo deficientes, além de estigmatizados como limitados em relação à sua capacidade de aprendizagem e de se posicionar diante de si mesmo, do outro e da própria vida (DOREA, 2008, p. 4).

Concomitante ao pensamento de Dorea (2008), Brandão (2002, p. 5) destaca a educação pedagógica dialética proposta por Freire numa perspectiva inclusiva e agente de transformação social, assim explicitada:

A relação dialógica preconizada por Freire deve ser revisitada por todos aqueles que fazem educação e que buscam a inclusão como arma de transformação da sociedade que temos, para aquela que queremos, pois o referido autor é e sempre será um exemplo para a educação (inclusiva) brasileira porque calca no verdadeiro diálogo a relação interativa, pautada pelo compromisso político de seus pares (BRANDÃO, 2002, p. 5).

Ao pensar esta concepção, a relação interativa entre educandos e educadores dá-se a partir de um processo reciproco de aprendizagem, onde o/a professor/a ao ensinar aprende e o/a aluno/a, numa contrapartida, ao aprender também ensina. Esta relação de troca de saberes pauta-se na pedagogia dialética, como pontuada anteriormente, baseada no princípio da igualdade. A construção do saber, pensada nesta perspectiva, não deve ocorrer através de posturas autoritárias e verticalizadas, mas fundamentar-se na autonomia, na liberdade e na valorização dos conhecimentos adquiridos e apreendidos pelos educandos e no respeito à realidade social na qual estão inseridos. Cabe ressaltar que a expansão do contexto social do qual fazem parte possibilita a transformação dos sujeitos que vivenciam a inclusão.

Gosto de ser gente porque, mesmo sabendo que as condições materiais, econômicas, sociais e politicas, culturais e ideológicas em que nos achamos geram quase sempre barreiras de difícil superação para o cumprimento de nossa tarefa histórica de mudar o mundo, sei também que os obstáculos não se eternizam (FREIRE, 2013, p. 53).
Configura-se, a escola desenvolvida na perspectiva da pedagogia dialética, como autora de uma inclusão real de todos/as, humanizando os educandos e o mundo, possibilitando condições indispensáveis para que alunos/as com ou sem deficiência conquistem e reconheçam-se enquanto sujeitos na construção e apreensão do conhecimento.

\section{Pedagogia montessoriana e a abertura do ensino para a criança com deficiência}

Em um período onde sutilmente abordava-se sobre a educação das pessoas com deficiência, nasceu Maria Montessori, na Itália em 1870. Foi reconhecida em seu país por ser a primeira mulher a formar-se em Medicina pela Universidade de Roma, em 1896, logo foi convidada a trabalhar no Hospital San Giovanni enquanto assistente (NICOLAU, 2005). Tezzari (2009, p. 117) complementa que:

Começa também a exercer a profissão com atendimento particular e continua, ao mesmo tempo, na clínica Psiquiátrica de Sciamanna, trabalhando com os médicos Sante De Sanctis (pai da neuropsiquiatria italiana) e Giuseppe Montessano. Foi nesse trabalho que nasceu o seu interesse pelas crianças retardadas ${ }^{6}$. É importante destacar que, nesse periodo, ainda era bastante incipiente a distinção entre doença mental e deficiência mental.

A partir desse contato com crianças com deficiência intelectual, segundo Schwegman (1999), que Montessori conduziu seu interesse pela pedagogia e a educação de pessoas com deficiência. Montessori (1965) relata que ao interessar-se pelas crianças com deficiência, aproximou-se do método criado por Edouard Séguin, e, mais tarde, dos relatórios de Jean Itard. Para ela, os estudos de Séguin forneceram o que denominou de "a chave secreta" (1965) para a educação das pessoas com deficiência: o amor. Partindo disto, rompeu com os ideais da ciência positivista de uma postura neutra e distante em relação ao objeto de estudo, e compreendeu que a deficiência não era exclusivamente uma questão médica, mas também consideravelmente pedagógica. Considerando esta questão, dedicou-se a estudar os métodos já existentes para educar as crianças com deficiência (TEZZARI, 2009).

6 Terminologia utilizada pela autora. 
Aprofundando-se às obras de Séguin e Itard, conforme descreve Pessotti (1984), Montessori apresentou no Congresso Pedagógico de Turim em 1898 uma proposta de trabalho que defendia a "educação moral para o ensino de crianças com deficiência mental". Destaca-se, ainda, que apesar desta proposta assemelhar-se com a defendida por Séguin, o que propunha Montessori é de fundamental contribuição para a pedagogia e para a educação das pessoas com deficiência (PESSOTTI, 1984). Montessori entendia que o método de educação para crianças com deficiência "deveria ir além da eficácia didática e alcançar a pessoa do educando, sua autoafirmação, seus níveis de aspiração, sua autoestima e sua autoconsciência. Sua ideia era de adequar a didática aos aspectos motivacionais relacionados ao educando" (TEZZARI, 2009, p. 119). Afirmou, então:

Era patente a necessidade de uma educação científica para as pessoas com deficiência: os anormais e inadaptados à sociedade não podiam compreender instruções nem executar ordens; urgia, pois, tentar outros meios mais adequados à capacidade de cada um. Essa educação seria uma pesquisa, uma experiência científica, um esforço para possibilitar a cada um a frequência regular à escola, propiciando meios e estímulos capazes de despertar energias latentes e reintegrá-las definitivamente na vida consciente, intensificando-as e coordenando-as mediante exercícios individuais (MONTESSORI, 1965, p. 37).

Após ser aceita com êxito a proposta de trabalho apresentada no Congresso Pedagógico de Turim, Montessori assumiu a direção da Scuola Magistrale Ortofrênica di Roma, local onde se formavam professores/as para lecionar para crianças com deficiência intelectual. Anexo a esta escola, funcionava o instituto médico-pedagógico a fim de realizar experimentos didáticos com crianças com deficiência para, então, aperfeiçoar os métodos educativos (SCHWEGMAN, 1999). Cabe ressaltar que nesta escola ofereciam-se atividades educativas para crianças vindas de escolas regulares e de "manicômios". A proposta pedagógica era realizada por meio de estímulos aos sentidos sensoriais, utilizando-se materiais didáticos especiais. Referindo-se a estes materiais, Montessori (1965, p. 31-32) assim afirmou:

\begin{abstract}
Esse material era maravilhoso instrumento nas mãos de quem dele se soubesse servir [...] Compreendi, logo, a razão do desânimo dos educadores e o consequente abandono do método. A convicção de que o educador deve colocar-se no mesmo nivel do educando levava-o a uma espécie de apatia: ele sabe que educa personalidades inferiores e é por isso que não os consegue educar. Da mesma forma, os professores dos "jardins de infância" julgam que se devem colocar no mesmo nivel das crianças, participando dos seus jogos, chegando mesmo a usar, muitas vezes, uma linguagem pueril. É necessário, justamente, proceder de maneira contrária, sabendo fazer despertar na alma infantil o homem que ai se acha adormecido.
\end{abstract}

As crianças com deficiência que passaram a vivenciar a educação a partir do método criado por Montessori, escola referida anteriormente. obtiveram os mesmos resultados nos exames escolares realizados nas escolas regulares. Com isto, Montessori concluiu a eficácia do seu método e passou a questionar a qualidade da educação oferecida nas escolas regulares, ampliando, assim, a sua proposta pedagógica (ANTUNES, 2005). Montessori traz significativos avanços para a educação do/a aluno/a com deficiência, pois possibilita o entendimento de que os/as alunos/as com deficiência também possuem potencialidades e estas precisam ser trabalhadas pela escola. Se a escola o subestimar, limitará o seu desenvolvimento. As escolas segregatórias que até então predominavam são exemplos desse limite no atendimento às demandas dos/ as alunos/as com deficiência. Montessori, a partir da sua abordagem, passou a permitir que os/as alunos/as com deficiência pudessem vivenciar a educação, tanto quanto as demais crianças e adultos. Seguindo o método montessoriano entende-se que as vivências são a chave para o processo educativo de qualquer sujeito, logo separar, segregar alguns em razão das suas características é um processo "antieducativo".

Antunes (2005) sintetiza, ainda, que Montessori baseou-se na direta observação da criança, das suas vivências e dos seus comportamentos para então apreender a sua natureza. A partir disto, rompeu com a concepção de que a criança deve ser vista e considerada como um "homem em miniatura", relatado por Aries (1981). Montessori 
conferiu à criança uma natureza singular, que não deve ser equiparada à condição de adulto, nem a um adulto incompleto, mas sim um "embrião" de adulto, dotado de potencialidades que precisam seguir o curso próprio, naturalmente, sem repressões. Sendo assim, acreditava que a educação tinha a finalidade de auxiliar as crianças a emergirem suas potencialidades interiores, com foco na personalidade, para, assim, construir o método educativo.

Montessori acreditava, baseando-se nesse método educativo, em um ambiente escolar com um espaço planejado para o acolhimento das espontâneas atividades dos educandos, que atendesse as necessidades para o pleno desenvolvimento das crianças ancorado pelos principios de liberdade, atividade, independência, individualidade e respeito. A sua proposta pedagógica deu-se, inicialmente, a partir do trabalho com crianças com deficiência intelectual, e já afirmava (começo do século XX) que elas aprendiam do mesmo modo que aquelas consideradas "normais", distinguindo-se apenas pelo ritmo de cada uma (TEZZARI, 2009). Essa afirmação não pode ser considerada irrelevante, uma vez que ao analisar os dados dos/as educadores/as que trabalham com crianças com deficiência atualmente, percebe-se muitos deles acreditam que as crianças com deficiência não são capazes de aprender, ou aprendem apenas certas atividades limitadas. Os princípios da pedagogia montessoriana podem ser considerados universais, uma vez que podem ser aplicados em qualquer espaço de escolarização formal.

\section{Considerações finais}

O momento histórico atual é de grande relevância no que se refere ao acolhimento das demandas das pessoas com deficiência. A mídia, os movimentos sociais que buscam a garantia dos direitos das PCD, as leis, vem demonstrando que é imprescindivel pensar no atendimento as necessidades de todas as pessoas. Para isto, apresentam-se as políticas públicas como estratégia que acenam para a possibilidade de dar conta das necessidades de inclusão de todas as pessoas. Os primeiros sinais de proteção ao operariado aconteceram na Alemanha, ainda no final do século XIX, com o consentimento da lei do seguro-acidente (1884) lei do seguro-invalidez e velhice (1889), como estratégia para alcançar o apoio e simpatia dos trabalhadores alemães, apontando afastá-los dos ideais socialistas. As péssimas situações de trabalho e de vida dos trabalhadores, ocasionadas pelo acirramento da questão social refletidas no aprofundamento das diferenças sociais consequente das guerras mundiais e da crise do capitalismo de 1929, estimularam o reconhecimento da obrigação de conceder proteção social a algumas categorias, dentre elas as pessoas com deficiência.

O avanço das políticas sociais, que cada vez mais facilitam o acesso a serviços para as PCD, bem como o progresso da ciência, facilitaram a sobrevivência, antes devastada em consequência de doenças, abandono ou execução. Após a grande disputa mundial, ${ }^{7}$ um número significativo de cidadãos com diferentes deficiências, em sua maioria heróis de guerra, que perderam a saúde e a incolumidade física protegendo a pátria, passaram a exigir dos países respostas eficazes às suas demandas. Especialmente os/as cidadãos da Europa e dos Estados Unidos. Esse foi um importante avanço na luta coletiva por direitos para as pessoas com deficiência.

Porém, sabe-se que as políticas sociais para além de servirem como instrumento de garantia de direitos, também têm características que afirmam o modelo de produção vigente, corroborando o binômio inclusão/exclusão que a diversidade humana está exposta. A partir da segunda metade do século passado, características no modo de vida das pessoas com deficiência passaram a ser reconhecidas. Isto passou a ser percebido na implementação de políticas públicas, na adaptação de prédios de uso público, na

\footnotetext{
Segunda Guerra Mundial (1939 a 1945). O lider alemão de origem austríaca Adolf Hitler, Führer do Terceiro Reich, pretendia criar uma "nova ordem" na Europa, baseada nos princípios nazistas da suposta superioridade alemã, na exclusão - e supostamente eliminação física incluida - de algumas minorias étnicas e religiosas, como os judeus e os ciganos, bem como pessoas com deficiência física e homossexuais; na supressão das liberdades e dos direitos individuais e na perseguição de ideologias liberais, socialistas e comunistas.
} 
contratação da mão de obra das pessoas com deficiência entre outros. Essas medidas foram conquistadas, determinadas pelo Estado para garantir a cidadania das pessoas e facilitar a Inclusão. Pode-se perceber que o Estado apenas respondeu às pressões da categoria, que está cada vez mais organizada, no entanto ainda não houve a formação de um sistema determinado e estruturado nacionalmente, que atenda integralmente as necessidades das PCD.

O atendimento às demandas de todos os sujeitos sociais deve deixar de ser uma preocupação a ser dividida entre governantes, especialistas e grupos delimitados de cidadãos e passar a ser uma questão fundamental para a sociedade. A questão se torna complexa quando se depara com a realidade de uma sociedade, que demanda soluções de sustentação e viabilidade para sua própria pluralidade, e esta na sua essência não é uma sociedade inclusiva. Longe disto, sabe-se o quanto instituições criadas para regrar o convivio entre os/as homens/mulheres tendem a reforçar a discriminação e a criar territórios que classificam e hierarquizam os cidadãos justamente a partir de suas diferenças. As pessoas com deficiência são historicamente identificadas como "diferentes" em função de um conjunto de igualdades mais ou menos constantes que acabam por definir seu lugar na sociedade, ou seja, lugar de exclusão.

Problematizou-se a pedagogia freireana, por entender que esta foi um marco no sistema educacional. A partir da sua ascensão, as barreiras que permitiam o acesso à educação apenas para as elites da sociedade, começaram a ser rompidas. Freire buscou refletir sobre a necessidade de garantir a educação para toda a sociedade. partindo do projeto de educação para adultos, este permitiu que outros setores, antes esquecidos pelas políticas públicas, também pudessem lutar pela garantia ao acesso à educação. Neste sentido, a sua contribuição para que os/ as alunos/as com deficiência também tenham acesso à educação, é evidente. Uma população historicamente oprimida agora passa a reivindicar o que lhes é direito. Do mesmo modo, a pedagogia montessoriana, poucas vezes lembrada, trouxe grandes contribuições para a inclusão da pessoa com deficiência, e os seus preceitos, se utilizados poderão garantir as vivências necessárias para que os/as alunos/as com deficiência sejam incluidos a partir da politica de educação.

No Brasil, as ações do Estado visando implementação das políticas públicas de atendimento as pessoas com deficiência iniciam sua organização no fim da década de 1980, início da década de 1990. A educação especial, por meio de diferentes abordagens de atendimento às deficiências possibilitou constatar diferentes modelos. Nesse contexto, Sassaki (1997) refere-se aos mesmos caracterizando-os como "médico" e "social". No modelo médico de deficiência, a mesma é encarada como doença, para a qual poderia haver possibilidade de cura; a deficiência é caracterizada como um problema da pessoa, e assim, essa pessoa deve adaptar-se à sociedade ou ser reabilitada ou curada. O diagnóstico da referida deficiência passa a ter uma importância singular, comparando-se à atividade médica. Sassaki (1997, p. 29), ao fazer a crítica ao modelo médico, afirma que este "tem sido responsável, em parte pela resistência da sociedade em aceitar a necessidade de mudar suas estruturas e atitudes". Para o autor, esse modelo constitui a fase de segregação e de integração, que implica em incorporar pessoas com deficiência no sistema de ensino, considerando o processo de adaptação centrado em suas próprias características.

O modelo social remete à perspectiva de que a deficiência deve ser concebida na sociedade e não na pessoa, neste sentido, a sociedade deve sofrer adaptações para dar conta das necessidades de todas as pessoas, pois não há possibilidade de transformação no processo de desenvolvimento individual, mas sim na sociedade em que o indivíduo está inserido.

\section{Referências}

ANTUNES, Mitsuko Aparecida Makino. O embrião do espirito. In: Viver mente e cérebro. São Paulo: Duetto Editorial, 2005. (Coleção Memória da Pedagogia Montessori).

ARIES, Philippe. História social da criança e da familia. Rio de Janeiro: Zehar, 1981. 
BRANDÃO, E.P. Por que não falar em educação inclusiva? In: REUNIÃO ANUAL DA ASSOCIAÇÃO NACIONAL DE PÓS GRADUAÇÃO E PESQUISA EM EDUCAÇÃO (ANPEd), 25., Caxambu, 2002. Anais eletrônicos [...]. Caxambu: ANPED, 2002. Disponivel em: http://Www. anped.org.br/reunioes/25/texced25.htm. Acesso em: 22 de março de 2015

BRASIL. Convenção sobre os Direitos das Pessoas com Deficiência. Protocolo Facultativo à Convenção sobre os Direitos das Pessoas com Deficiência. Brasilia, DF: Corde, 2007.

CARDOSO, Marilene da Silva. Educação Inclusiva e diversidade: uma práxis educativa junto a alunos com necessidades especiais. Porto Alegre: Redes Editora, 2008.

DOREA, Gumercindo R. F. Paulo Freire e a educação para todos, 2008. Disponivel em: http://Www.paulofreire.org/ twiki/pub/FPF2008/TrabalhoGumercindoRochaDoreaFilho/Proposta_de_trabalho_para_o_forum_paulo_freire_Guga_Dorea_LATINUS.doc. Acesso em: 22 mar. 2015

FERNANDES, Idilia. Relações sociais no convivio com as diferenças e deficiências numa perspectiva histórica. In: LIPPO, Humberto (org). Sociologia da acessibilidade política das diferenças. Canoas: Ed. ULBRA, 2012.

FLETCHER, Agnes. Ideias práticas em apoio ao Dia Internacional das Pessoas com Deficiência: 3 de dezembro. Tradução Romeu Kazumi Sassaki. São Paulo: Prodef/Apade, 1996.

FREIRE, Paulo. Pedagogia da indignação: cartas pedagógicas e outros escritos. São Paulo: Editora UNESP, 2000.

FREIRE, Paulo. Pedagogia da Autonomia. Saberes necessários à prática educativa. 46. ed. Rio de Janeiro: Paz e Terra, 2013.

FREIRE, Paulo. Pedagogia do Oprimido. 56. ed. Rev. e atual. Rio de Janeiro: Paz e Terra, 2014.

GOFFMAN. Ervin. Estigma. Notas sobre a manipulação da identidade deteriorada. Tradução Mathias Lambert. Digitalização 2004. [S. l.: S. n.]: 1891.

GOFFMAN, Erving. Manicômios, Prisões e Conventos Tradução Dante Moreira Leite. 7 ed. São Paulo: Editora Perspectiva, 2001

IBGE. Instituto Brasileiro de Geografia e Estatística (IBGE). Censo demográfico 2010. IS. l.]: IBGE. Disponivel em http://cens02010.ibge.gov.br/. Acesso em: 2015.

JORGE, J. A ideologia de Paulo Freire. São Paulo: Loyola, 1979

LOBO, Lilia. Ferreira. Os Infames da História: a instituição das deficiências no Brasil. 1997. 2 vol. Tese (Doutorado) - Departamento de Psicologia da Pontifícia Universidade Católica do Rio de Janeiro, Rio de Janeiro, 1997.

LUIZ. Danuta Estrufika Cantoia. Rupturas moleculares emancipatórias: A potencialidade da prática do Serviço Social. 2012. Tese (Doutorado) - Pontificia Universidade Católica de São Paulo, São Paulo, 2012.

KALAKUN, Jacqueline. Pessoas com Deficiência. In: OLIVEIRA, Jairo da Luz. (org.). Políticas Sociais Especificas. o1ed. Canoas: ULBRA, 2010, v. 01, p. 01-144.

KRUPPA, Sonia M. Portella. Sociologia da Educação. São Paulo: Cortez, 1994.
MANTOAN, Maria Teresa Eglér. A integração de pessoas com deficiência: contribuições para uma reflexão sobre o tema. São Paulo: Memnon/Senac, 2003.

MENDES, Enicéia G. Integração escolar: reflexões sobre a experiência de Santa Catarina. InterAção, Brasilia, DF, v.5, n.12, 1994

MISÉS, R.A criança com deficiência mental: uma abordagem dinâmica. Rio de Janeiro: Zahar, 1977.

MONTESSORI, Maria. Pedagogia Cientifica. São Paulo: Flamboyant, 1965

NICOLAU, Marieta Lúcia Machado. A formação de Maria Montessori. In: Viver mente e cérebro. São Paulo Duetto Editorial, 2005. p. 6-15. (Coleção Memória da Pedagogia Montessori).

ONU. Organização das Nações Unidas. A ONU e as pessoas com deficiência. [S. l.: S. n.]: [201?]. Disponivel em http://nacoesunidas.org/acao/pessoas-com-deficiencia/. Acesso em: 2015.

PEREIRA, Potyara. Politica Social. Temas \& questões. 2. ed. São Paulo: Editora Cortez, 2009.

RUBIO, Claudia Grau. Educación especial: De la integración a la escuela inclusiva. Valencia: Promolibro, 1998.

SASSAKI. Romeu Kazumi. Inclusão. Construindo uma sociedade para todos. 8. ed. Rio de Janeiro: WVA, 1997.

SASSAKI, Romeu Kazumi. Atualizações semânticas na inclusão de pessoas: Deficiência mental ou intelectual? Doença ou transtorno mental? Revista Nacional de Reabilitação, [s. l.], ano 9, n. 43, p. 9-10, mar./abr. 2005

SOARES, Leonardo Humberto. Descobertas arqueológicas no Iraque ajudam a decifrar a evolução da espécie humana. Revista Net: História, para compreender, registrar e formar,[s. l.], 2015.

STAINBACK, Susan; STAINBACK, Willian. Inclusão: Um guia para educadores. Porto Alegre: Artes Médicas, 1999.

TEZZARI, Mauren Lúcia. Educação Especial e Ação Docente: da medicina à educação. 2009. Tese (Doutorado) - UFRGS, Porto Alegre, 2009.

WERNECK, Claudia. Muito prazer, eu existo. 4. ed. Rio de Janeiro: WVA, 1995.

ZITKOSKI, Jaime. A Pedagogia freireana e suas bases filosóficas. In: GHIGGI, Gomercindo; SILVEIRA, Fabiane; PITANO, Sandro. Leituras de Paulo Freire: contribuições para o debate pedagógico contemporâneo. Pelotas: Seiva, 2007. p. 229-248.

\section{Jocenir de OLiveira Silva}

Doutor em Serviço Social (PUCRS), em Porto Alegre, RS, Brasil. Professor Adjunto da Universidade Federal do Pampa (Unipampa), no Curso de Serviço Social, em São Borja, RS, Brasil. Componente do Grupo de Pesquisa em Políticas Sociais, Questão Social e Relações de Exploração/Opressão. 


\section{Idilia Fernandes}

Doutora em Serviço Social pela Pontificia Universidade Católica do Rio Grande do Sul (PUCRS), em Porto Alegre, RS, Brasil. Assistente Social da Fundação de Articulação e Desenvolvimento de Políticas Públicas para Pessoas com Deficiência e com Altas Habilidades no Rio Grande do Sul, em Porto Alegre, RS, Brasil.

\section{Luísa Righi Fonseca}

Mestre em Políticas Públicas pela Universidade Federal do Pampa (Unipampa), em São Borja, RS, Brasil. Assistente Social, especialista em Politica de Assistência Social - SUAS pelo Centro Universitário Internacional, em São Borja, RS, Brasil. Componente do Grupo de Pesquisa em Politicas Sociais, Questão Social e Relações de Exploração/Opressão.

\section{Endereço para correspondência}

Jocenir de Oliveira Silva

Universidade Federal do Pampa

Rua Ver. Alberto Benevenuto, 3.200

9767000

São Borja, RS, Brasil 